\title{
Investigation of the DEMO WCLL Breeding Blanket Cooling Water Activation
}

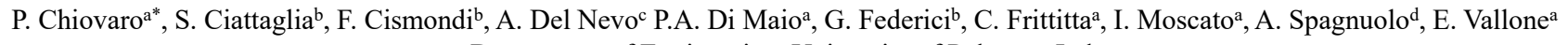
${ }^{a}$ Department of Engineering, University of Palermo, Italy

bEUROfusion Consortium, Boltzmannstr.2, Garching, 85748, Germany

${ }^{c}$ ENEA C.R. Brasimone, I-40032 Camugnano (BO), Italy

${ }^{d}$ Karlsruhe Institute for Technology (KIT), Hermann-von-Helmholtz-Platz 1, 76344 Eggenstein-Leopoldshafen, Germany

\section{ABSTRACT}

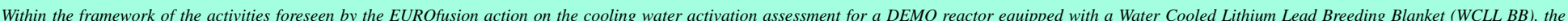

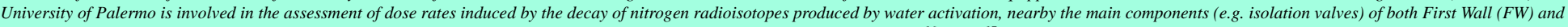

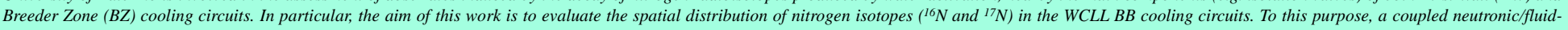

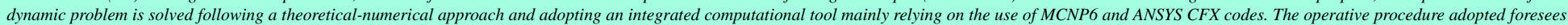

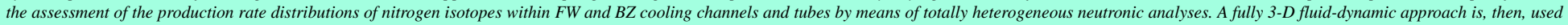

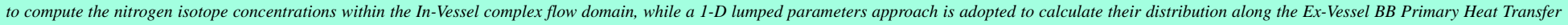

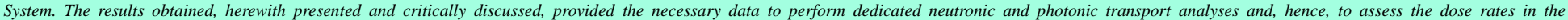
aforementioned target locations.

\section{Introduction}

Within the framework of the activities foreseen by EUROfusion actio on the "Cooling water activation assessment", the University of Palerm is involved in the assessment of the absorbed dose around both First Wall (FW) and Breeder Zone (BZ) cooling circuits (e.g. isolation valve hot and cold legs) of the DEMO reactor equipped with a Water Coole Lithium Lead Breeding Blanket (WCLL BB).

\section{Description of the method}

The operative procedure adopted is based on a multi-physics method previously developed and it foresees the assessment of the spatial distribution of nitrogen isotope concentration production rates with FW an BZ cooling channels and tubes by means of completely heterogeneous neutronic models. A fully 3-D CFD approach is, then, used to compute the nitrogen concentrations within the In-Vessel complex flow domain, while a lumped parameters, 1-D approach, is adopted to calculate the nitrogen isotope concentrations along the ExVessel BB PHTS.

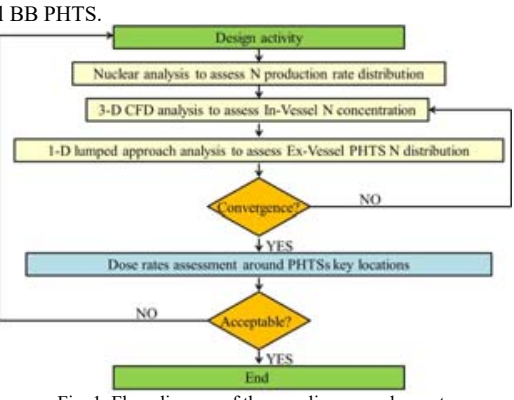

Fig. 1. Flow diagram of the coupling procedure set-up.

3. Assessment of the volumetric density of ${ }^{16} \mathrm{~N}$ and ${ }^{17} \mathrm{~N}$ production rates

The first step of the procedure described above foresees the assessment of the spatial distribution of ${ }^{16} \mathrm{~N}$ and ${ }^{17} \mathrm{~N}$ volumetric density production rates, therefore, neutronic analyses have been carried out for the cooling circuits of $\mathrm{OB}$ and IB FWs and for the OB BZ circuit while results have been extrapolated for the IB BZ circuit, which has not been considere as its design is not still mature enough.
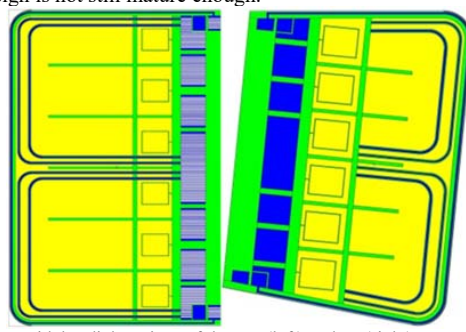

Fig. 2. Toroidat radits (rions of the OB (left) and IB (rigt) MCNP models.

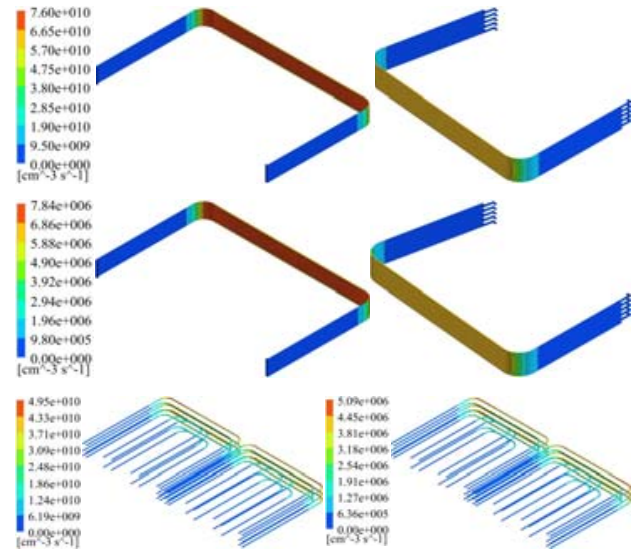

Fig. 2. Spatial distribution of ${ }^{16} \mathrm{~N}$ and $1^{7} \mathrm{~N}$ volumetric density production rates in the $\mathrm{OB}$ and $\mathrm{IB} F W$ and in the $\mathrm{OB} \mathrm{BZ}$

4. ${ }^{16} \mathrm{~N}$ and ${ }^{17} \mathrm{~N}$ volumetric densities

The assessment of ${ }^{16} \mathrm{~N}$ and ${ }^{17} \mathrm{~N}$ volumetric densities in the $\mathrm{FW}$ channel of the $26 \mathrm{OB}$ and $55 \mathrm{IB}$ slices has been performed by CFD analyses. A far as BZ tubes are concerned CFD analyses have been performed in one $\mathrm{OB}$ slice and results have been extrapolated to the whole segment scaling the values in accord to NWL neutron profile. Nitrogen isotopes concentrations of the IB BZ water domain have been obtained from the OB BZ ones using scale factor taking into account both the ratios between the different NWL values and the mass flow rates related to the $\mathrm{IB}$ and $\mathrm{OB}$ segmen

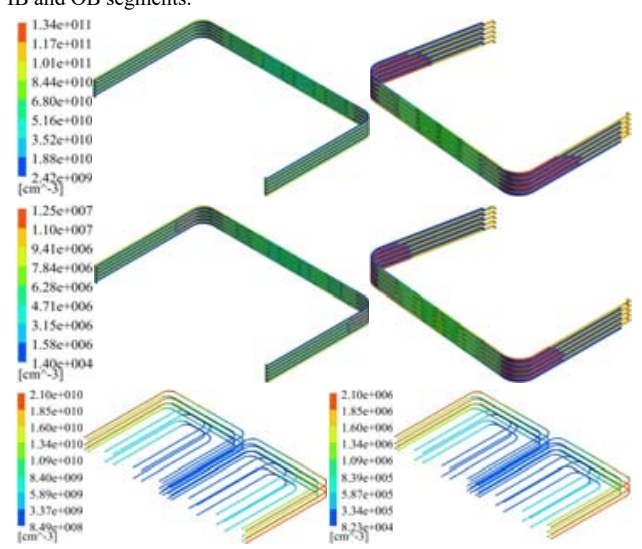

Fig. 3. Spatial distribution of ${ }^{16} \mathrm{~N}$ and ${ }^{17} \mathrm{~N}$ volumetric density in the $\mathrm{FW}$ and $\mathrm{BZ}$.
The assessment of ${ }^{16} \mathrm{~N}$ and ${ }^{17} \mathrm{~N}$ concentration spatial distributions in the Ex Vessel components has been carried out by a numerical method based on a 1-D lumped parameter approach that foresees a nodalization of the system. As nitrogen isotopes move from the single slice to the entire cooling system, it is necessary to account for the mixing of water streams in the collector pipes that transfer the coolant water to the PHTS, modifying the nitrogen concentration distribution along the cooling system. So, each slice, pipe and component of the cooling com is modelled as a node. Basically, for each node, it has been what exits to the next nodes, decreased by the amount of nitrogen lost due to decay during the transit.
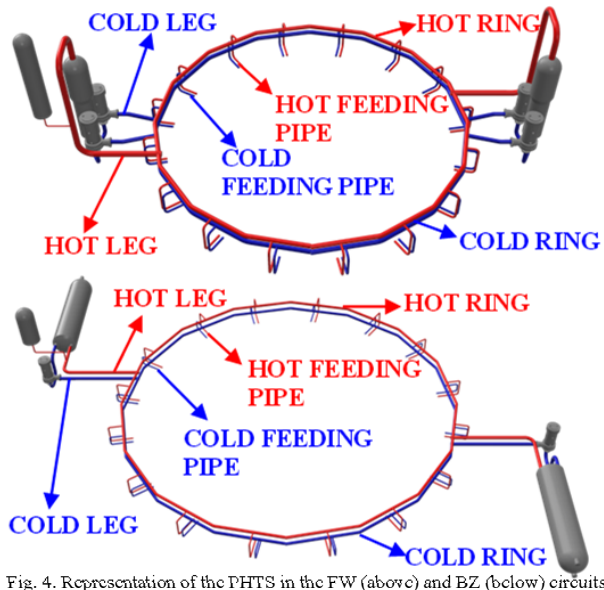

\begin{tabular}{|c|c|c|}
\hline NODE & ${ }^{16} \mathrm{~N}$ & ${ }^{17} \mathbf{N}$ \\
\hline Hot Feeding Pipe & $3.809 \mathrm{E}+10$ & $2.338 \mathrm{E}+06$ \\
\hline Hot Ring & $3.031 \mathrm{E}+10$ & $1.616 \mathrm{E}+06$ \\
\hline Hot Leg & $2.922 \mathrm{E}+10$ & $1.518 \mathrm{E}+06$ \\
\hline Cold Leg & $5.248 \mathrm{E}+09$ & $8.077 \mathrm{E}+04$ \\
\hline Cold Ring & $5.060 \mathrm{E}+09$ & $7.589 \mathrm{E}+04$ \\
\hline Cold Feeding Pipe & $4.928 \mathrm{E}+09$ & $7.257 \mathrm{E}+04$ \\
\hline \multicolumn{3}{|c|}{ Table 2. Nitrogen concentration in the $\mathrm{BZ}$ circuit $\left[\mathrm{cm}^{-3}\right]$. } \\
\hline NODE & ${ }^{16} \mathbf{N}$ & ${ }^{17} \mathbf{N}$ \\
\hline Hot Feeding Pipe & $4.516 \mathrm{E}+09$ & $3.008 \mathrm{E}+05$ \\
\hline Hot Ring & $3.519 \mathrm{E}+09$ & $2.012 \mathrm{E}+05$ \\
\hline Hot Leg & $2.578 \mathrm{E}+09$ & $1.182 \mathrm{E}+05$ \\
\hline Cold Leg & $1.692 \mathrm{E}+09$ & $5.758 \mathrm{E}+04$ \\
\hline Cold Ring & $1.627 \mathrm{E}+09$ & $5.387 \mathrm{E}+04$ \\
\hline Cold Feeding Pipe & $1.577 \mathrm{E}+09$ & $5.107 \mathrm{E}+04$ \\
\hline
\end{tabular}

\section{CONCLUSIONS}

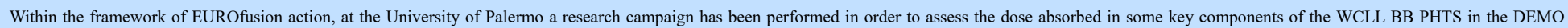

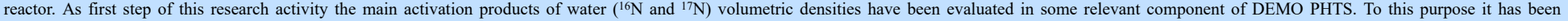

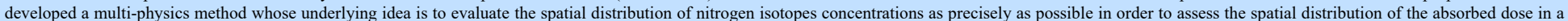

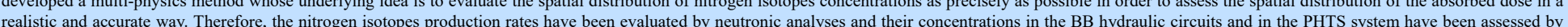

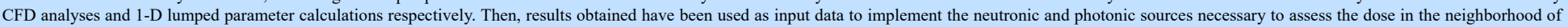
the PHTS in a further work. 